\title{
Regression and the maternal in the history of psychoanalysis, 1900-1957
}

\section{Shaul Bar-Haim}

Sometime in the late 1920s, Anna Freud told Sandor Ferenczi: "you really treat your patients as I treat the children whom I analyse" (Ferenczi 1930, p. 440). Ferenczi had to admit that she was right. The emergence of child-psychoanalysis after the First World War created a paradigmatic shift not only for the new professional child-psychoanalysts like Anna Freud, but also for the older generation of therapists, like Ferenczi, who treated mainly adults. Ferenczi was particularly interested in knowing more about the new 'child-patient', but nevertheless he believed that he already knew something about it through his own experience with 'regressed' adult-patients. 'Regression' became, in the 1920s, a major concept in the Ferenczian way of thinking, as well as a subject of debate in the psychoanalytical world as a whole. Ferenczi's late 1920s pioneering initiative to develop the concept of regression as a method of treatment took some of its inspiration from the new discipline of childpsychoanalysis, but very soon regression became a controversial issue among psychoanalysts, especially between Ferenczi himself and Freud.

Ferenczi was aware of the fact that, for analysts like him who treated mainly adults, child psychoanalytic techniques were relevant not only to understanding children but also in as much as they could be used to understand adult-patients who had entered into regressive states from their early past. On the one hand he "[had] very little to do with children analytically" (Ferenczi 1931, p. 469), but on the other hand he claimed that regressive treatments of adults could be very similar to the treatment of children. In 1931 he argued that "certain facts of analytic experience [have] grouped themselves in my mind round ideas 
which urge me to temper materially the antithesis, hitherto so sharp, between the analysis of children and that of adults" (ibid).A year later he wrote: "We talk a good deal in analysis of regressions into the infantile, but we do not really believe to what great extent we are right...The patient gone off into his trance is a child indeed who no longer reacts to intellectual explanations, only perhaps to maternal friendliness" (Ferenczi 1949 [1933], p. 227).

Reading Ferenczi's later writings might give the impression that Ferenczi had in mind three kinds of patients: the child patient, the conventional adult patient and the regressed adult patient. Since he had little clinical experience with child-patients, he tried to learn as much as he could from his clinical experience with regressed adult patients, in order to find some links between his work and that of his new contemporaries - the child-psychoanalysts. Therefore, his discussion with Anna Freud was not only an attempt to find some similarities between her child patients and his regressed adult patients, but was also part of his effort to legitimize his approach to regression as an active therapy with positive results. This re-enactment of childish behavior and Ferenczi's encouragement of this regressive state as a method of treatment explains his strong affinity with Anna Freud: they both assume that the childish mind is always a target for intervention by an authoritarian adult figure.

Regression itself, however, is a vague term. The Oxford English Dictionary defines it as a 'reversion to an earlier or less developed psychological state, either as a defensive response to circumstances, or as a result of hypnosis, psychoanalysis, or psychotherapy'. ${ }^{1}$ But one may fairly ask what it actually is in its psychoanalytical context. Is it only a general metaphor, used by the 'psy' professions to reveal one's mental-abnormalities? Is it an actual mental move backwards to concrete developmental stages in one's past? Or perhaps it is an everyday experience, which can describe the feeling of each one of us when we smell the cookies

${ }^{1}$ OED Online, http://www.oed.com/, accessed 14/9/2013. 
which remind us something of our mother's kitchen? In short, is it a pathological mental state or is it part of everyone's normal healthy mental condition?

Many answers have been given to these questions; the history of psychoanalysis provides us with different ways of thinking about regression. However, in this paper, I would like to examine the history of a particular line of thought about regression, namely the Ferenczian one. First, I will briefly review some of the intellectual sources of the notion of regression in early psychoanalysis as they were perceived by Ferenczi. Then, I will discuss the work of two of Ferenczi's best readers in early and mid- $20^{\text {th }}$ century British psychoanalysis, who tried to understand the more literal sense of the regressive experience. The first is Ian D. Suttie (1889-1935), who published his main works between 1924 and 1935. The second is Michael Balint, who came to England in 1939 from Budapest, but who published his main writings in the 1950s and 1960s. Their understandings of the term regression were slightly different, but nevertheless they both believed that it is impossible to define regression only in pathological terms; to some extant, they maintained, each one of us experiences regressive states frequently in our daily life.

In his Interpretation of Dreams, Freud distinguished between three kinds of regression:

(a) topographical regression, in the sense of the schematic picture of the $\psi[\mathrm{psi}]-$ systems $[\ldots]$; (b) temporal regression, in so far as what is in question is a harking back to older psychical structures; and (c) formal regression, where primitive methods of expression and representation take the place of the usual ones (Freud 1900, 548). 
In their dictionary of psychoanalysis, Laplanche and Pontalis state: 'Freud introduces the idea of regression in The Interpretation of Dreams (1900) in order to account for an essential characteristic of dreams: the dream-thoughts arise for the most part in the form of sensory images which impose themselves upon the subject in a quasi-hallucinatory fashion. The explanation of this trait calls for a topographical conception of the psychical apparatus which views it as made up of an ordered succession of systems. In the waking state, these systems are traversed by excitations in a progressive direction (travelling from perception towards motor activity); during sleep, by contrast, the thoughts, finding their access to motor activity barred, regress towards the perceptual system' (Laplanche and Pontalis 1973, p. 386). Formal regression is linked to the hierarchical structure of the psychical systems: regression from secondary to primary process is a major example. Temporal regression, according to Laplanche and Pontalis, 'denotes the subject's reversion to past phases of his development (libidinal stages, object-relationships, identifications, etc.)' (ibid.). In other words, to say that one is in a regressive state is to say that one behaves, and sometimes feels as if he really has returned to an earlier developmental stage as an infant, child or adolescent. Another important distinction made by Laplanche and Pontalis, is concerned with the difference between regression as a description, and regression as a literal phenomenon. Freud, as they pointed out, thought of regression as a descriptive concept, but a tradition developed in psychoanalysis of defining it in a much more literal way. As Laplanche and Pontalis maintained, it is not the same, for example, to describe someone as 'an obsessional subject [who] has regressed to the anal stage' as to say of a schizophrenic that he turned back 'into a baby at the breast' (ibid., p. 388). The former is a structural description of one's psyche, while the latter is an enactment of a person's most extreme feelings.

One of the main questions, then, regarding 'regression' is whether it was merely perceived by the psychoanalytical community and its related circles as a useful metaphor or whether there 
was a real belief in the regressive process as a scientific description of what takes place in the mind. In other words, how far did Freud and his followers conceptualise 'regression' as an actual phenomenon, as opposed to a manner of speaking about something more elusive. This is an historical question, since each of the psychoanalytic communities in Europe and elsewhere perceived the concept of regression in very different ways.

$$
* * *
$$

A full history of the evolution of the concept of regression would necessarily include notable nineteenth-century biologists, psychologists, and social-scientists, such as Lamarck, Darwin and Lombroso; this project is beyond our scope. For our purposes, however, perhaps the most relevant among these $19^{\text {th }}$ century figures is the German biologist, Ernest Haeckel. Haeckel was one of the main popularizers of Darwin in Germany, but by the second half of the $19^{\text {th }}$ century he himself had become very famous. By the middle of the $1860 \mathrm{~s}$, he developed his own theory of evolution, known as the theory of recapitulation, or as the 'biogenetic law'.

The theory of recapitulation was famously known for the claim that 'ontogeny recapitulates phylogeny'. Haeckel, who coined these terms, explained that 'phylogeny is the developmental history of the abstract, genealogical individual; ontogeny, on the other hand, is the developmental history of the concrete, morphological individual' (cf. Gould 1977, p. 80). Stephen Jay Gould explained Haeckel's theory as the view that 'an organism, during the course of its embryonic growth, passes through a series of stages representing adult ancestors in their proper historical order' (Gould 2002, p. 248). In other words, traits of the evolutionary

\footnotetext{
${ }^{2}$ On Haeckel's theory of recapitulation see Richards 2008, pp. 113-170; Gould 1977, pp. 76-85).One of Richards' claims in his book is that even though 'Haeckel's great sin in the eyes of many historians and philosophers is that he was not Darwin'(p. 13), he was still a loyal Darwinist.
} 
process of the humankind as distinct from other biological species can be found in each one of us. Haeckel thought of it mainly in physiological terms, but many other adherents, including Freudians adherents, wanted to take it even further and to claim a parallel between ontogeny and phylogeny also on the mental and psychological level. ${ }^{3}$

Freud, however, was not the only nineteenth century social theorist influenced by this 'theory of recapitulation'. Among those who adopted its principles were the biologist and political theorist Herbert Spencer ${ }^{4}$ (1820-1903) and his follower, the neurologist John Hughlings Jackson $^{5}$ (1835-1911). It is the latter who particularly emphasized that any notion of evolution must contain the possibility for the reverse process, that is, a process of 'dissolution'. This concept was crucial for his neurological theory of mental illness, since he described insanity as dissolution of the progressive regions of the mind towards an evolutionarily more primitive stage of the mind. It is no wonder that Freud was deeply influenced by Jackson's ideas ${ }^{6}$, and that he is considered by contemporary psychoanalytic literature as the precursor of the notion of regression (Blum 1994, pp. 61-61; Dowling 2004, pp. 197-201).

Ferenczi was no less enthusiastic about the possibility of synthesising Haeckelian notions with psychoanalysis. He considered himself to be 'an adherent of Haeckel's recapitulation theory, according to which the developmental history of the individual is an abbreviated repetition of the developmental history of the species' (Ferenczi 1924, p. 103). He claimed, however, that this theory could be used not only to explain phylogeny but also to explain the history of the entire species (palingenesis). In his book Thalassa (1924), Ferenczi suggested a new theory of parallelism between ontogeny, phylogeny and palingenesis, and thought that by

\footnotetext{
${ }^{3}$ On Freud and 'recapitulation' see Gould 1977, pp. 155-164; Otis 1994, pp. 181-205.

${ }^{4}$ See, Smith 1982a.

${ }^{5}$ See, Smith 1982 b.

${ }^{6}$ See Forrester 1980, pp. 1-39; Greenberg 1997, pp.117-158; Steiner p. 230
} 
this approach he could show that the theories of recapitulation and psychoanalysis were complementary.

There are some traces of his Freudian-Haeckelian ambitions in Ferenczi's very early psychoanalytic writings. In 1912, for example, he argued that déjà vu is a kind of regression into our primal stage as embryos. Our body recapitulates some traits of this historical phase of ours, and that trait can be revealed in a later stage as déjà vu. Ferenczi acquired much of this line of thought from his patients themselves. For instance, in a case published in 1912, he suggested to one of his patients that her sensitivity to her fiancé's bad smell was a reaction to his confession that he had been with other women before her. When Ferenczi gave his interpretation, she reacted by saying that she felt that moment, in the treatment room, as 'it has all happened to me before!' (Ferenczi 1912, p. 320). Ferenczi explained to her that she was having a déjà $v u$; she replied:

'We used to say [in our childhood] that the reason why things sometimes struck us as so familiar was because we had met them before, when we were still frogs!' I drew her attention to the fact that, when she was still a 'frog' (an embryo), she had really been in most intimate contact with another woman's body (her mother's), and moreover in close proximity with organs and excreta the smell of which (as I already knew) were extremely repulsive to her (ibid.).

Even though Freud did not mention the word déjà vu, it seems likely that seven years later, he was drawing on some of Ferenczi's ideas in his easy on the 'Uncanny'; he writes: 'there is a joking saying that "Love is home-sickness" and whenever a man dreams of a place or a country and says to himself, while he is still dreaming: "this place is familiar to me, I've been here before", we may interpret the place as being his mother's genitals or her body.'(Freud 
$1919,245) .{ }^{7}$ As we shall see later on, the idea of getting back to the womb had preoccupied the psychoanalytic discourse of regression for many years and in many ways.

In Thalassa, described by Freud as 'perhaps the boldest application of psycho-analysis that was ever attempted' (Freud 1933, p. 228), Ferenczi provided his most radical ideas on the 'regressive'. He put forward the hypothesis that the whole earth used to be one big ocean, where the only form of life was an idealized 'aquatic mode of existence'(Ferenczi 1924, 52). But the recession of the oceans created a huge catastrophe for all living things, and forced them to begin the evolutionary process of species development:

For, we reflected, what if the entire intrauterine existence of the higher mammals were only a replica of the type of existence which characterized that aboriginal piscine period, and birth itself nothing but a recapitulation on the part of the individual of the great catastrophe which at the time of the recession of the ocean forced so many animals, and certainly our own animal ancestors, to adapt themselves to a land existence, above all to renounce gill-breathing and provide themselves with organs for the respiration of air? (ibid., p. 45, italics in original) However, according to Ferenczi, it was not only the respiratory system which had to be provided: we can read the development of the entire human body as a response to this catastrophe. For instance, Ferenczi had no doubt that fish are not a symbol for the penis, as is traditional in many cultures, but the other way around: the penis was created by the evolutionary process to enact the life of a fish swimming in the water, in order to satisfy a human desire to regress into the timeless heavenly thalassic times. In fact, the act of coitus itself, suggested Ferenczi, is not only a mean of procreation, but the reliving of the 'aquatic mode of existence':

\footnotetext{
${ }^{7}$ In fact, Freud had already acknowledged his debt to Ferenczi on 'déjà vu' in a remark he added in 1910 to his third edition of The Psychopathology of Everyday Life (Freud 1901, pp. 267-268).
} 
It is possible for us to think of coitus and sleep as the conducting off of current traumatic stimuli and, at the same time, the expression of the striving to reproduce the intrauterine and thalassal situation seemingly long since transcended - nay, we could even perceive in them a return to still more archaic and primitive strivings towards repose... (ibid., pp. 84-85).

We can find here some of the views which Ferenczi developed in his discussions with Freud during World War I about the possibility of developing a Lamarckian psychoanalysis. As Freud wrote to Ferenczi in 22 December, 1916: 'our project, "Lamarck and $\Psi$ A," suddenly came to mind as hopeful and rich in content. I am predicting all kinds of things there and am actually already convinced about it. ${ }^{8}$ Almost a year later, in a letter to Karl Abraham of 11 November, 1917 Freud wrote:

Have I really not told you about the Lamarck idea? It arose between Ferenczi and me, but neither of us has the time or spirit to tackle it at present. The idea is to put Lamarck entirely on our ground and to show that his "need", which creates and transforms organs, is nothing but the power of Ucs. ideas over one's own body, of which we see remnants in hysteria, in short the "omnipotence of thoughts" (Falzeder 2002, p. 361).

Freud, however, did not find again after 1918 'the time or spirit to tackle' the subject and abandoned this ambitious project. It was Ferenczi alone who had to keep this speculative line of thought of putting 'Lamarck entirely on our ground'. For him, Lamarckianism was strongly related to his clinical attempts to achieve what he considered as the main goal of psychoanalytic research, that is, exploring the inner mechanism of psychosomatic phenomena

\footnotetext{
${ }^{8}$ While Darwin was mentioned by Freud frequently, Lamarck was mentioned only in his correspondence with others and mainly in his correspondence with Ferenczi during the War. With the publication of Freud's manuscript "Overview of the Transference Neurosis" (Freud 1915) - which was written in 1915, but was discovered only in 1983 by the German psychoanalyst Ilse Grubrich-Simitis - there were good reasons to believe in the major influence of Lamarck on Freud.
} 
- best exemplified by the 'hysteric woman', but after the War also by the 'shell-shocked soldier'. In hysteria, he said in 1921, 'the pathogenic psychic material of the hysteric can use the associated physical memory material [körperllicher Erinnerungmaterials] as a means of expression'(Ferenczi 1921a, p. 29). It is as if for Ferenczi 'physical memory' was the way to explain the regressive mechanism that enables hysteria - the mechanism of what Freud thought of as the 'omnipotence of thoughts'.

But 'physical memory' was also the missing link for showing that 'ontogeny recapitulates phylogeny' and how it works also on the mental level. As the philosopher of science Patricia Kitcher pointed out, "if Lamarck was right and recapitulation true, then it was reasonable to construe childhood and neurotic behaviour (which allegedly involved a regression to childhood forms) in terms of the practices and experiences of primitive humans; it was reasonable to hypothesize a primitive portion of the mind in which this material was stored" (Kitcher 2007, p. 241). It was precisely this mixture of psychoanalysis with HaeckelianLamarckian evolutionism that many scientists and social theorists fiercely rejected. One of them was the Scottish psychiatrist, Ian D. Suttie, who criticized Freud's psycho-biological speculations in Beyond the Pleasure Principle (Suttie 1924), but his critique was equally valid when directed to Ferenczi's Thalassa. Rather than thinking of regression in biological terms, Suttie - who was in many other respects one of Ferenczi's admirers in Britain suggested that we consider regression as much more a social-cultural concept. However, before getting into Suttie's views on regression, a brief review of the usage of 'regression' in British psychoanalysis in the interwar period would be useful.

As with Freud and Ferenczi, who developed their views on regression in the light of earlier, nineteenth-century biological models, many early twentieth century British psychiatrists and 
psychologists also gave priority to biology in discussing this topic. Many interwar British social scientists tended to describe the human condition as a continuing struggle between primitive animal instincts and the 'human will' (Loughran 2007). W.H.R Rivers, for instance, defined regression as a state 'in which an instinctive process characteristic of infancy persists in its capacity for activity in later years' (Rivers, 1922, p.152). Moreover, he perceived regression as a collapse of the 'controlling forces' (Rivers, 1922, p. 119) of the mind, and the returning of man to a much more primitive stage in biological evolution.

The psychoanalytical view of regression was not so different from this mainstream medical approach - not surprisingly, since Rivers had worked under Jackson in 1890 and explicitly drew on his work; they all tended to believe in some primal biological instincts as the source of the regressive phenomena (Loughran, 14-15). But the question was not necessarily what is the best way to define regression, but in what cases regression can be used and in what context. The popular British psychologist William McDougall, for instance, used this term 'in a purely descriptive sense, without meaning to imply any theory of the process or condition' (McDougall 1920, p. 136). What is more, he argued that his interest in publishing cases of severe regression of shell-shock soldiers, was precisely because

Among all the wealth of cases presenting an immense variety of combinations of symptoms and conditions, these cases, in which the dominant feature is regression to early childhood, seem to have been comparatively rare, and the nature of the condition and of the processes involved in its onset remain to my mind obscure and deserving of further discussion (ibid.).

McDougall addressed this statement directly to those psychoanalytical circles that used regression in a much more metaphorical sense and for much wider purposes. ${ }^{9}$ Indeed, this

\footnotetext{
9 'I have been told that it is improper to use the word [regression] in this fashion, because the Freudians have annexed it for their exclusive use. I cannot assent to such surrender of the words of our language'(ibid).
} 
word had become part of the psychoanalytic jargon in clinical descriptions of patients ${ }^{10}$; but in that period people were also using it as part of their attempts to deploy psychoanalytic theory in other disciplines of the humanities and the social sciences. This was the case, for example, in the study of delinquency, which became very dominant in interwar Britain. Criminality was not anymore only a moral sin, but also a sign of psychological regression. Many interwar researchers into delinquency took the psychoanalytic view and explored the 'analogy between criminal acts and childish phantasies' (Klein 1927, p. 191). Roger Money-Kyrle, for example, explained that according to psychoanalysis there are three developmental stages - oral, anal, and genital - but only the normal individual 'has reached the final stage' (Money-Kyrle 1928, p. 280), while the neurotic and the pervert 'are fixed at a more primitive level' (ibid.). He maintained that '[these] pre-genital characters fall roughly into two types - the incompetent and criminal. The repressions of the criminal will only permit him to function anti-socially' (ibid.). And so Edward Glover, the leading figure among psychoanalysts in the study of adolescent delinquency, claimed that 'drug-addiction acts as a protection against psychotic reaction in states of regression' (Glover 1932, p. 315).

Regression in its psychoanalytic sense was perceived as a culturally induced condition responsible for much of abnormal, pathological and anti-social behavior. Recognizing people's regressive states became central to the interwar understanding of, and the development of solutions to, all sorts of medical-social problems, specifically to all kinds of antisocial behavior, 'from bed-wetting to train-wrecking' (Winnicott 1957, p. 117), to use Winnicott's phrase.

\footnotetext{
${ }^{10}$ Thus, for example, S. M. Payne described in a typical language one of her patients as following: 'He had entered the phallic phase and had partially regressed after puberty. The inability to establish adult genitality was due to regression to a fixation in the oral and anal phases' (Payne 1939, p. 165). Or, James Glover (Edward's brother) had a patient who had to 'drink increasingly large quantities of alcohol till his narcissistic regression over-invested his homosexuality en route'(Glover 1927, p. 22). Melitta Schmideberg, however, suggested in 1935 more caution in using this term (a statement which also can tell us tell us something about the popularity of regression among analysts). In her work on children's bad habits, she argued that some of these habits 'are regarded as substitutes for masturbation. Though they show the same structure it is not justifiable to regard them only from the point of view of regression' (Schmideberg 1935, p. 456).
} 
Regression became also a popular concept for analysts in their cultural observations. Ella Sharpe, for example, gave her psychoanalytic interpretation of Hamlet, claiming that 'the study of the particular nature of the regression gives us an understanding of that 'Hamlet' quality which makes the Oedipus situation in his case so peculiarly fascinating and individual' (Sharpe 1929, p. 270). Ernest Jones wrote in his essay on chess that 'all games are apt at times to be marred by unsportsmanlike behaviour, i.e. by the sublimation undergoing a regression to its asocial origins, but with chess the strain is exceptionally great' (Jones 1931, p. 5). David Eder in his historical-sociological paper 'The Myth of Progress', said that 'we refuse to recognize that this myth is but a regression to an infant's phantasy now enthroned in our super-ego. Once upon a time it was an introjected authority; now it figures as something independent - God, Progress, our Higher Self' (Eder 1932, p. 9).

It was only after the Second World War that we can recognize a shift in the psychoanalytic discourse in Britain in the usage of regression from metaphorical register to that of the real studying regressive phenomena as legitimate experiences for scientific investigation. The word regression was used less to describe unacceptable behaviour, and much more to designate a real mental state, now perceived as an unavoidable state in some circumstances which can appear in each of us at some stage in our lives. Ian Suttie was in many respects a precursor of these trends within post Second World War psychoanalysis.

Suttie was born in Glasgow, and received his medical degree from Glasgow University in 1914. After the outbreak of the First World War he joined the Royal Army Medical Corps, and served in France and the Middle East. After the war he returned to become a psychiatrist at the Glasgow Royal Asylum, where he also met his wife, the psychiatrist, Dr Jane Robertson. In 1928 Ian joined the Tavistock Clinic in London as a clinical assistant, and in 
1933 he was appointed a full member of staff (Jane was appointed a clinical assistant at Tavistock in 1931). Henry Dicks, who worked with Ian Suttie at Tavistock, remembered him as 'a lively spirit who soon organized private discussion meetings in which Tavistock staff were engaged in most amicable but also quite rigorous doctrinal discussions with their psychoanalytic "opponents"' (Dicks 1970, p. 40). However, in 1935 he died, when he was only 46. 'His premature death was much mourned by us', writes Dicks (ibid.).

We have some good reasons to think that Suttie was a good reader of Ferenczi, and that the latter did influence the way in which he thought of regression. First, his wife and co-author, Jane Isabel Suttie, translated the second volume of Ferenczi's writings into English (Ferenczi 1926); as they were working closely, they probably did share some of Ferenczi's ideas between themselves. ${ }^{11}$ Suttie also referred to Ferenczi in his writings a few times, though not as frequently as one might expect. Finally, Suttie shared some of Ferenczi's ideas and approaches in his clinical technique. He appreciated what he considered as the main Ferenczian contribution - the notion that 'it is the physician's love that heals the patient' (Suttie 1935a, 75).

His only book, The Origins of Love and Hate (Suttie 1935a), together with a few earlier articles, contains a radical critique of the Freudian concept of the father as the origin of sociability in human beings. It is the mother and not the father, argued Suttie, who is responsible for our basic mental orientations towards other people. In her relations with her infant, the mother is the one who creates the paradigm for sociability in the infant's mind. The relationship with the mother precedes any other kind of relationship and, according to Suttie, it is the only relationship which is originally 'natural' and not socially constructed. For example, claimed Suttie, there is nothing essentially 'natural' in some socio-cultural premisses

\footnotetext{
${ }^{11}$ In the preface of this volume, Ferenczi was very grateful to Jane for her translation, saying that she 'has not flinched from the toil of following the train of my thought with so much understanding' (Ferenczi 1926, p. 9).
} 
about the superiority of man over women, or the father over the mother, in modern patriarchal society. On the contrary, the only thing which is essentially 'natural' in a newborn infant is his or her 'simple attachment-to-mother who is the sole source of food and protection' (Suttie 1935a, p. 15).

The father, according to Suttie, plays a role only after this basic bond between the mother and her infant has already been created. He is excluded from the initial natural intimacy between the mother and her child, and therefore he develops a strong jealousy of their relationship. This new way of looking at the father enables Suttie to turn the entire Oedipal structure on its head:

[In the Oedipus complex] the child's incestuous desire then would serve as an excuse for the father's interference, disguising his own regressive jealousy. We are not for a moment implying that the conditions described by Freud do not in fact exist...We hold, however, that this conflict is not the necessary and universal state of affairs that Freud imagines it to be; that the initial jealousy does not come from the child and is not of a genital nature, but rather springs from the associative impulse (Suttie and Suttie 1932, p.212).

The jealousy which Suttie described leads to patriarchal society, or what Ian and Jane Suttie described as 'Oedipus culture', which 'manifests itself in anti-feminism, anti-sexuality, a neurotic dread of mother incest and of mother-worship, and therefore in a propitiatory father worship and the attribution to a paternal god of all creative and moral powers' (Suttie and Suttie 1932, p. 230). It was this Oedipus culture that brought Suttie to suggest the motherinfant bond not only as an alternative model for a better psychoanalysis ${ }^{12}$, but also as an

\footnotetext{
${ }^{12}$ It is these views, unusual within psychoanalytic circles in the 1920s and 1930s, which have brought about a renewal of interest in Suttie from some scholars in the last decade, who see him as one of the Ur-theorists of the British school of psychoanalysis. See Gerson 2004; Gerson 2009b; Clarke 2006; Miller 2007; Cassullo 2010.
} 
utopian starting point for creating a better society - a society which will not suffer from what Suttie described as 'the taboo on tenderness' (Suttie 1935, pp. 80-96). This idea - central to Suttie's thought - was probably referring to Ferenczi's famous last article, 'Confusion of the Tongues between the Adults and the Child - (The Language of Tenderness and of Passion)' ['Sprachverwirrung zwischen den Erwachsenen und dem Kind. Die Sprache der Zärtlichkeit und der Leidenschaft '] (Ferenczi 1949[1933]).

However, it is important to note that even if Suttie was a strong protagonist of the 'maternal', it does not necessarily mean that he was a feminist in its modern sense. Suttie idealized some matriarchal pre-modern societies, because 'if matriarchal cult, myth, theology, initiation ritual and sacrifice deal with and give expression predominantly to regressive longings and jealousies, the patriarchal equivalents deal mainly with precocity and repression'(Suttie 1935a, p. 133). However, when Suttie comes to explain what matriarchy actually is, he describes it as 'a society where the woman is the effective head of the household' (ibid., p. 120). According to Suttie, the mother is the ruler of the children, and she has to get the full recognition for that. Once she is fully empowered, and restored to her old position as the 'ruler of the household' - as was allegedly the case in some old matriarchal societies - children will grow up in a much more positive, social and loving environment, without the damaging influence of an envious father. These children will be much more capable, claimed Suttie, of living together with other people, with decisive social consequences. In contrast to what he perceived as Freud's tendency to dismiss the role of the mother, Suttie suggested maternity as a possible way of getting back into the communal harmony which he believed characterized the pre-modern period.

In his article 'Religion: Racial Character and Mental and Social Health' (Suttie 1932), Suttie made the distinction between pre-Christian Teutonic cultures, which were based on love, and western patriarchal cultures, which were based on guilt. In this context Suttie gave a special 
place to Judaism, the source for the religions of the father, that is, the religions of guilt. Christianity, according to Suttie, is also essentially patriarchal, but, at least in its early versions, it emphasized and encouraged love and brotherhood among its believers as its main set of values. It is precisely these values, so important for early Christianity, that were absent in Judaism, Lutheranism and Calvinism. ${ }^{13}$ By enforcing their patriarchal ideology, he claimed, these religions created the conditions for some damaging individualistic forms of life, which did not exist before the modern age. For example, possessiveness and the need for property in its modern sense, are a direct consequence of the 'forced renunciation of the primal baby-mother intimacy', which creates 'dissatisfaction with, and distrust of, the social environment which comes gradually and more or less adequately to fill the place in affective life originally occupied by the mother'(Suttie 1935b). This primal loss of the intimacy with the mother creates an anxiety about loneliness and solitude, and an existential fear that the basic social needs of the individual will be ignored. This feeling of helplessness could be the source for destructive behaviour, but not the other way around. According to Suttie, no one has any 'death instinct', as Freud believed, or any other primal destructive instincts, as argued by Melanie Klein; aggressive behaviour arises only after the loss of the 'mother rapport'. That is to say, love exists before any hate, jealousy or envy appears.

In order to support his claim, Suttie examined a wide range of myths and folklore from pre-modern European societies and 'primitive' cultures; some of his writings are a mixture of mythologies, descriptions of cults and ethnological explanations from many different places. As a result, his concept of the 'pre-Western-modern' seems many times to be more imaginative and idealized than historical and real, and it is not always clear which premodern society exactly Suttie is longing for. However, among all these non-Jewish, nonprotestant and non-modern old traditions, his deepest appreciation was, perhaps, for what he

\footnotetext{
${ }^{13}$ See, Gerson 2009a, p.28.
} 
imagined to be the 'pagan' culture, because of what he thought as the positive approach of pagans to regressive phenomena:

Psychologically, one might describe 'the pagan' as taking parental love for granted. He is willing, therefore, on the one hand, to surrender the privileges of infancy for the responsibilities of adulthood, while unafraid, on the other, to take and enjoy the pleasure and privileges of the latter state. He has steered his development between the Charybdis of infantile regression and the Scylla of Oedipus-precocity, and so he is left without distrust in himself or unconscious fear of incurring parental wrath and separation (Suttie 1935, p. 155).

For Suttie, then, the only reason why regression was perceived as a pathological phenomenon was because of the ways in which notions of 'infancy' and 'adulthood' are construed by western modern societies. These societies, he claimed, are dominated by the denunciation of the first attachment of the child to his mother. Therefore, any regressive phenomenon in adulthood is perceived as an attempt to recover this primal bond with the mother, and therefore as a threat to the paternal order.

Looking at the history of pre-modern cultures can suggest some positive ways of thinking about regression in people's daily lives. Suttie considered that many people wrongly perceived regression as a symptom of deeper pathology. He maintained that as it was a legitimate and understandable mental state in the past, it could also be so again in the future, in a different sort of society with different sorts of values. Indeed, for him, a regressive state could be a sign of a healthy relationship in a healthy family. He took the view as we have already noted, that healthy families are those which have not abandoned the importance of the maternal role. However, this notion of maternity as a primary paradigm for any kind of healthy social relationship had its full impact within the British psychoanalytic movement only after the Second World War, with the work of Michal Balint, D.W. Winnicott (1896- 
1971) and John Bowlby ${ }^{14}$ (1907-1990). Balint, who was known in Britain and elsewhere as Sandor Ferenczi's most remarkable pupil and successor, will be the topic of the last section of this paper.

Before the Second World War, Michael Balint was one of the senior members of what was known today as the psychoanalytic 'Budapest School', famous among other things for its psychosomatic approach, that is to say, bringing the body to the fore in psychoanalytic discourse. It was also known for its interdisciplinary approach, and some of its members were pioneering figures in applying psychoanalysis to other disciplines, particularly in anthropology (see Moreau-Ricaud 1996; Vikar 1996; Young-Bruehl 2002). But the psychoanalytic movement in Budapest was also a target for the fascist regime throughout the interwar period, and many of its senior members left during this time to Berlin and New York. Balint, however, stayed in Budapest after 1924, and became the senior figure in Hungarian psychoanalysis after Ferenczi's death in 1933. By the beginning of 1939 he too was forced to leave Budapest and managed to arrive to London with his wife Alice - herself a psychoanalyst. He was obliged to requalify to practise in Scotland before he got a job as a 'child guidance clinic director' in Manchester, where Alice died. After the war, Balint moved to London, where he was appointed to the Tavistock institute, and later on he opened his own private practice. During the 1950s and 1960s he was recognized as one of Britain's leading psychoanalysts, and in 1968 he was elected to be the president of the British PsychoAnalytical Society. ${ }^{15}$

Like his teacher, Ferenczi, Balint also claimed there were crucial therapeutic advantages in bringing patients to a state in which they relived scenes from their childhoods, and sometimes

\footnotetext{
${ }^{14}$ Bowlby was also the only one among the leading figures of 1950s psychoanalysis in Britain, who fully acknowledged his debt to Suttie. See, Cassullo 2010, p. 7.

${ }^{15}$ See, Moreau-Ricaud 2002.
} 
behaved as if they really had become children again. But he also claimed that we experience regressive states all the time in our everyday lives, and recognizing these mental dispositions can help us to improve our social life in the public sphere.

For him, the regressive state of some people reflects an inherent 'confusion of tongues', which exists in any authoritarian relationship: between parents and their children, in the class room at school, between workers and their managers, etc. This concept of 'confusion of tongues' was taken by Balint from the title of Ferenczi's article, published first in 1933 (Ferenczi 1949[1933]), in which Ferenczi claimed that the paradigm for any mental trauma is a primal 'confusion of tongues' between the child and his parents. That is to say, that there is a traumatic gap between any child and her mother and father, since the child requires many things which she cannot achieve without internalizing her parents' inner self and making his or her own psychic structure adjust to theirs. In other words, the child is forced not only to imitate the parents' conscious language, behaviour and social norms, but also their unconscious ones. This confusion of tongues is the source of many regressive states in life, when a person in a relationship of authority re-enacts a very private mode of maladjustment to authority derived from his own initial developmental stages. Ferenczi, however, believed that severe regressive states can be treated only through regression itself. Only regression can enable the patient to enact her initial traumatic events, and so emancipate her from her own traumatic confusions of tongues.

Here is the place to say a few words about the ambivalent attitude of psychoanalysis towards regression as a therapeutic tool, derived in part from its historical link to nineteenth century hypnosis. Freud did not want psychoanalysis to be associated in anyway with hypnosis. From a medical perspective, he considered it as an unreliable treatment; from an ethical point of view, he saw it as an abusive procedure. According to Freud, 'hypnotic treatment seeks to 
cover up and gloss over something in mental life; analytic treatment seeks to expose and get rid of something. The former acts like a cosmetic, the latter like surgery' (Freud 1917, 450).

After the First World War, Ferenczi introduced his new 'active technique'(Ferenczi 1919; 1921; 1924), which made him reconsider the Freudian distinction between 'hypnotic treatment' and 'analytic treatment'. In his 'active technique', Ferenczi suggested that in some specific cases, the doctor should intervene more actively in the process of free-association. For example, he told some 'patients whose symptoms consist in habitual day-dreaming forcibly to interrupt these phantasies and to exert all their force in seeking out those psychical impressions which have been avoided through fear (phobically), and which have switched the patients over on to the tracks of pathological phantasy' $(1924,69)$. Ferenczi, however, insisted that these new interventionist methods are not taken from the hypnotic tradition, and are 'invulnerable to the reproach that one is mixing the method of free-association with the procedures of suggestion' (ibid.). By using 'active technique', he said, 'we do not deem the interpretations we offer to be irrefutable utterances, but regard their validity to be dependent on whether they can be verified by material brought forward from memory or by means of repetition of earlier situations' (ibid., 69-70). For Ferenczi, then, the 'talking cure' brings patients to regressive states ('repetition of earlier situation') in which they reconstruct traumatic events of their past during their analysis. Moreover, these regressive states can guarantee the reliability of the analytic process itself. In that respect, he considered some regressive elements in the relationships of the analyst and his patients to be unavoidable.

Ferenczi, however, had another problem with his 'active technique'. In order not to become a 'hypnotist', he tried to keep some distance from his patients in order not to abandon his medical objectivity. However, as Balint stated many years later, 'Ferenczi had to admit to his patients that producing the repetition of the traumatic situation by his active intervention, and 
then watching the events with the customary sympathetic detachment was very similar in its structure to the original trauma' (Balint 1979 [1968], 125). In other words, the 'active technique' created a role-playing, in which the patient took the role of herself in the traumatic event, and the doctor took the role of her offender. It was at this point that Ferenczi started to believe that a more benevolent participation of the doctor in this regressive role-playing can be a real step forward towards a cure. Rather than repeating the role of an offender from the past - usually the patient's carer - the doctor could and should play the role of the good parent that the patient never had.

By the late 1920s, many of Ferenczi's followers considered regression as a necessary therapeutic tool for mediating the past and the present of the patient, tracing back her traumatic events, and helping her cure by taking an active parental role in the regressive situation at the treatment-room. We can see that while Freud insisted that regressive procedures run the risk of the analyst falling into the trap of hypnosis, and become a 'hypnotist' instead of an analyst, Ferenczi was much less cautious regarding regression: for him regression was the core of the treatment itself.

For Balint, too, the line between 'regressed patients' and 'children' was not always clear; sometimes these two categories had become for him totally conflated. Balint was trying to be a good parent for his adult-patient, that is to say, to give back the adult-patient the good parenting of which she had been deprived. He attempted to do that by replacing parental authority, in the role of the analyst, by parental love in order to create a paradigm of a parent who is not an educator but solely a source for 'maternal love', or what he would define as a 'primary love'. The psychoanalyst, according to Balint, has to fulfil the primary maternal needs of his adult-patients, such as the feeling of 'the baby in its mother's arms', the feeling of 
'being in love' and the 'feeling of oneness with the universe' (Balint 1955, p. 231). ${ }^{16}$ This approach, however, led Balint to blur the line between adult and child patients and in the end to treat them almost the same.

Here are two examples of Balint's almost interchangeable usage of the terms 'infant' or 'child' and the term 'regressed patient' (italics are mine):

It is only at this point that I have to go farther and use my findings to infer from them what might happen in pre-verbal periods, that is in early 'childhood' and in deeply regressed states. This is a more uncertain, more controversial, field, as we all know. The cause of this uncertainty is the dependence of the subject, baby or patient, on his environment, that is on the observer. In both situations-earliest 'childhood', highly regressed patient—-the dependence on the environment is an essential factor.

The young baby and the regressed patient live in a pre-verbal state, and thus we, who set out to be emotionally uninvolved scientific observers, become not only participants and partners, but also interpreter-informants, and finally translators (ibid., p. 229).

Balint really believed that the infant and the regressed patient are in the same situation: both of them, he claimed, are in a pre-verbal stage. On the one hand Balint was aware of the fact that a patient - unlike the infant - 'can come back from it [and] can tell something of what

\footnotetext{
${ }^{16}$ In what follows, I am drawing on Balint's article 'Friendly Expanses-Horrid Empty Spaces' (1955), which was incorporated later into Thrills and Regressions (1959), one of his better known books. Balint developed some of his ideas from that period in his later work, The Basic Fault: Therapeutic Aspects of Regression (1968). This current article, however, focuses on Balint's earlier work, of the 1950s, and therefore The Basic Fault will not be discussed here.
} 
happened to him in his own words' (ibid., p. 237). On the other hand, when the patient is in the state of regression itself, he or she 'is beyond the world of words' (ibid.). So whenever the patient is not in a regressed stage he is different from the infant in every possible mental aspect, but once he is regressed he becomes no different from the infant in any aspect at all. According to Balint, the parent/analyst's role is to translate their infants'/patients' pre-verbal languages into the language of the adults' world.

But he also defined parents and analysts as inevitably the teachers and the educators of their infants/patients: 'both the baby and the regressed patient in the end have no choice but learning to speak the language — i.e. vocabulary and grammar-of the adult on whom they dependent, the baby for his life, the regressed patient for his restoration' (ibid., p. 230).

The infant is inherently dependent on the adult because he is in a pre-verbal stage and therefore lacks any language to communicate with adults. Therefore, Balint says that 'both the baby and the regressed patient have to learn from us how to express themselves so as to be understood first by us, then by themselves, and ultimately by their fellow-men' (ibid., p. 237). The parent/analyst also becomes the child's educator and teacher, whether he likes it or not. The only parental disposition which does not involve practicing any sort of authority is that of the baby in its mother's arms.

'When we start the treatment' he writes 'we offer a set-up to our patients which in almost every case induces them to adopt a babyish posture' (ibid. p. 238). This 'babyish posture' is the state that the regressed patient should reach:

These [regressed] patients feel as if they were wrapped up in some cosy, warm, structureless darkness which envelops them and protects them from the unsympathetic and unfriendly external world, represented quite often by the analyst (ibid, p. 237). 
Here Balint is explicitly suggesting abolishing even the small perceived gap between regressed patients and infants and treating the one as we would treat the other.

One of the main signs of a successful regressive treatment, claimed Balint, is if the patient demands that his analyst maintains almost complete silence in the consulting-room and does not allow the analyst to interrupt with any interpretations. Balint pointed out that silence could be an expression of anxiety and lack of communication between people, but it also could be a sign of harmony, peacefulness, confidence and growth. In the context of regressive treatments, silence is an expression of a mental state before the pre-verbal stage, the stage in which the infant is not even aware of his lack of language. But, one might ask, what is this 'pre-preverbal' stage? Is there any developmental stage before the preverbal stage, other than that of the embryo's existence in the womb? This is the only stage where we had no language but that was not a problem - because all our needs were supplied to us biologically by our mothers.

Balint claimed that the 'analyst should become part and parcel of the patient's world. In fact not a separate object at all, but should merge as completely as possible into the '"friendly expanses" surrounding the patient' (ibid., p. 239). Does this not mean that the treatment room could really supply a regressive experience of this initial integrated stage of the mother and her embryo? And is the womb not the only place where the parent-child relationship can be seen as not being grounded in dependency, authority, lack of language on one side and imposition of language on the other?

Balint's approach to regression was not limited to his private patients, and he claimed the importance of acknowledging and recognizing people's regressive states also in the public sphere. At the beginning of the 1950s, Balint and his third wife, Enid, established an innovative peer group for general practitioners. Their initial idea was to create a group where 
physicians would be able to discuss their practical work and particularly their 'psychological implications in general medical practice'(Balint 1968 [1957], p. 1). The group included fourteen general practitioners and a psychiatrist. They met once a week in London to discuss case studies, namely their patients' stories, which were brought by each participant. The group included fourteen general practitioners and a psychiatrist. They met once a week in London to discuss case studies, namely their patients' stories, which were brought to the meetings by each participant. Many cases, however, revealed to the doctors that their patients often served only as triggers for debate, and that the real 'case-studies' were the doctors themselves - who found themselves investigating the long-term doctor-patient relationship from a very personal perspective. The group also tracked the development of each case in the weeks, months, and sometimes years to come. This work with practitioners led Balint to publish in 1957 his book The Doctor, His Patient and the Illness, describing the story of the first 'Balint group', which has since been the model for Balint groups around the world.

The theoretical presumption behind Balint's work was that there is no such thing as a medically objective diagnosis, but rather the diagnosis is always an inter-subjective process negotiated by the doctor and his patient. Thus, the doctor and his patient are always in a process of negotiation over the right way to describe a set of symptoms, name them and finally treat them.

In his book, Balint demonstrated the ways in which general practitioners began to think more 'psychoanalytically', particularly by seeing their patients through the lens of regression. Balint believed that regressive situations require doctors to recognize that they are taking part in psychological role-playing exercises designed to recreate of their patient's past. More awareness of regressive states might enable doctors to understand better their most demanding patients, and also to learn whether it is possible to 'read between the lines', so to speak, to discover a patient's needs - in terms of body and mind. He suggested that general 
practitioners learn how to recognize regressive situations in patients as indications that patients need help; and he also suggested that GPs should not look at situations solely from the outside but should take a positive role in bringing regressive states to the surface and by trying to respond to patients' regressive needs as much possible.

We must also remember that regression in psychoanalytic thought can be seen as another form of 'transference'. By transference I mean what Freud defined as a situation when 'a whole series of psychological experiences are revived, not as belonging to the past, but as applying to the person of the physician at the present moment' (Freud 1905, p. 116). In other words, transference is a form of symbolic replacement and role-playing, just as some regressive situations could be. The patient replaces a formative person from his past with a symbolic authoritarian figure from his present, and thereby creates psychological roleplaying. This is the form of role-playing which can take place also between the doctor and his patient.

For instance, a young female patient had complained of indigestion for three years. When she came to ask for tablets, her general practitioner plucked up the courage to ask her a few more personal questions. After a short discussion he found out that her father left when she was five, and that she had suffered from a domineering mother. The general practitioner gave her the opportunity to come and speak with him regularly every week, and his influence on her was tremendous. After a while she found the courage to confront her mother, and became engaged to her boyfriend, whom her mother didn't like. In that stage all her physical symptoms had almost vanished (Balint 1964 [1957], pp. 182-184). However, much of the discussion in the group was not about the case itself but rather on what Balint described as 'Dr. R's rather forceful offer of himself as a father-substitute to his patient'(ibid. P. 184). Dr. R. did not hesitate to suggest his own views concerning some of his patient's most personal issues. For instance, he encouraged her not to feel ashamed of having sexual relationships 
with her fiancé; on this issue, as in other sensitive questions, he had 'deliberately turned against the mother and sided with his daughter-patient against her' (ibid., pp. 184-185). According to Balint, the main achievement of the group in this case was to show Dr. R. the ways in which he 'was acting as an understanding, forgiving and powerful father. It was uncertain to what extent the patient should be made fully conscious of this, but it was certain that Dr. R. must become fully conscious of his role' (ibid., p. 188). ${ }^{17}$ The doctor must be conscious of his role not only to prevent any sort of inappropriate treatment but also because this role itself was flexible and can be changed all the time in the long relationship between the doctor and his patient.

Balint used another case study to demonstrate his belief that the general practitioner must be able to provide flexible medical functions according to the patient's changing needs:

When the psychotherapeutic relationship is broken off he [the doctor] changes back into a doctor; then he becomes a psychotherapist again, then changes back into a doctor, and then into an obstetrician... and finally turns into a "friend of the family". During all this he has helped an impossibly immature, severely hysterical neurotic to grow up into an efficient woman, a wife and, very likely, quite an acceptable mother (ibid. p. 169).

We can see how Balint was mainly pleased when the general practitioner recognized his patient's wish to enter into this regressive role-playing with him, and also with his consent in participating. This case involves the doctor taking the role of the father, but in fact Balint thought that the paradigm for any kind of therapy is the maternal relationship between the mother and her baby. This approach was very much in line with other psychoanalytic writers

\footnotetext{
${ }^{17}$ Indeed, awareness was not only a medical injunction, but as Thomas Osborne pointed out, it was an ethical one. Drawing on the later work of Michel Foucault he argues that for Balint it is the self-labour itself that is to be taught. And central to this teaching will not be any moral rules or codes laid down by the doctor, but the exemplarity of the doctor'(Osborne 1993, p. 191).
} 
of the period, such as Winnicott and Bowlby, as well as Ian Suttie before them. The common belief of these post Second World War theorists was that only the mother can supply an infant with continuous care which goes beyond language into a full understanding of his or her physical and mental needs.

This new 'maternal' way of thinking can be demonstrated by the following case. MR. P. was a very disturbed patient who became obsessively attached to, as well as completely dependent on Dr. H., his devoted general practitioner. After much effort, Dr. H. managed to help him overcome many of his inhibitions, including his obsession with her. The participants in the group discussed whether she could then revert back to her old role as a 'family doctor' to him and to his family. Balint concluded this discussion by comparing the role of the general practitioner to the role of the mother: 'After all, mothers have to go on being mothers all their lives' (ibid, 210) — the implication being that the maternal role could never be relinquished.

We can see that all the thinkers who have been discussed in this present paper claimed a strong linkage between regression and the maternal role. Ferenczi believed that déjà vu is a regressive enactment of a foetus's feeling in the mother's womb. This feeling, he believed, is part of an even wider regressive tendency of people towards an idealized archaic age where the entire world was one big ocean. Being in the mother's womb, he proposed, is not only an idealized time in itself, but a reliving of the best time of all in the evolutionary process of humanity. Ian Suttie portrayed a slightly different picture of the regressive tendency of people towards the maternal. The main problem for modern society, he claimed, is that it is extremely patriarchal, but also anti-maternal, since it does not leave any room for regressive feelings and regressive behaviour to recapture the initial bond of the mother and her baby. Finally, Michael Balint thought of the therapist as a provider of the maternal dimension to 
people who have been deprived of good parenting, and who have therefore developed certain kinds of regressive needs. But to some extant, he thought, we have all been deprived from perfect mothering and we all have regressive tendencies.

In 1968, two years before he died, Balint published his book, The Basic Fault: Therapeutic Aspects of Regression, which in many respects summarizes his theoretical work on regression. This book, however, also provides us with Balint's perspective of what one might call the history of the 'Ferenczian movement', in which the history of the concept of regression occupies a central place. Let him have the last word:

The general view at [the time when Ferenczi died] was that [his] experiments had shown that responding to a regressed patient's cravings was a mistake; it caused endless and useless troubles both for the patient and the analyst, and was anyway condemned by Freud. For some time I tried to reopen the case by pointing out that this wholesale condemnation was both unjust and unprofitable. What I asked for was a critical reappraisal - not an uncritical acceptance - of what was valuable in the ideas developed in Budapest under Ferenczi's leadership. There was no response. Having failed, the only policy remaining to me was to continue with my clinical work and test the validity of these ideas by further experience. In recent years I think there have perhaps been some signs of a change in the general attitude, though I may be mistaken. So I am trying again (Balint 1979 [1968], p. $133)$.

\section{References}

Balint, M. (1955) 'Friendly Expanses-Horrid Empty Spaces'. International Journal of Psycho-Analysis 36: 225-241. 
Balint, M. (1964 [1957]) The Doctor, His Patient And The Illness. London: Pitman Medical.

Balint, M. (1959) Thrills and Regressions. New York: International Universities Press.

Balint, M. (1979 [1968]) The Basic Fault: Therapeutic Aspects of Regression. London:

Tavistock Publications.

Blum, H. P. (1994) 'The Conceptual Development of Regression'. Psychoanalytic Study of the Child 49: 60-79.

Cassullo, G. (2010) 'Back to the Roots: The Influence of Ian D. Suttie on British

Psychoanalysis', American Imago 67(1): 5-22.

Clarke, G. S. (2006) Personal Relations Theory: Fairbairn, McMurray and Suttie. London: Routledge.

Dicks, H. V. (1970), Fifty Years of the Tavistock Clinic. London: Routledge \& Kegan Paul. Dowling, A. S. (2004) 'A Reconsideration of the Concept of Regression'. Psychoanalytic Study of the Child 59:197-201.

Eder, M. D. (1932), 'The Myth of Progress', British Journal of Medical Psychology 12(1):114.

Falzeder, E. (2002) The Complete Correspondence of Sigmund Freud and Karl Abraham 1907-1925. London and New York: Karnac.

Falzeder, E. and Brabant, E. (1996) The Correspondence of Sigmund Freud and Sandor Ferenczi Volume 2, 1914-1919. Cambridge, MA and London: The Belknap Press of Harvard University Press.

Ferenczi, S. (1912) 'A case of 'Déjà vu'. In S. Ferenczi, Final Contributions to the Problems and Methods of Psycho-Analysis. London: Hogarth Press, 1955, pp. 319-320. 
Ferenczi, S. (1919). 'On the technique of psycho-analysis'. In S. Ferenczi, Further

Contributions to the Theory and Technique of Psycho-Analysis. London: Hogarth Press, 1950, pp. 177-189.

Ferenczi, S. (1921a) 'Psycho-Analytical Observations on Tic'. International Journal of Psycho-Analysis, 2:1-30

Ferenczi, S. (1921b) 'The Further Development of an Active Therapy in Psycho-Analysis. In S. Ferenczi, Further Contributions to the Theory and Technique of Psycho-Analysis. London: Hogarth Press, 1950, pp. 198-217.

Ferenczi, S. (1924) 'On Forced Phantasies'. In S. Ferenczi, Further Contributions to the Theory and Technique of Psycho-Analysis. London: Hogarth Press, 1950, 68-77.

Ferenczi, S. (1989[1924]) Thalassa: A Theory of Genitality. London: Karnac.

Ferenczi, S. (1926) Further Contributions to the Theory and Technique of Psycho-Analysis. London: Hogarth Press.

Ferenczi, S. (1930) 'The Principle of Relaxation and Neocatharsis'. International Journal of Psycho-Analysis 11:428-443.

Ferenczi, S. (1931), 'Child-Analysis in the Analysis of Adults'. International Journal of Psycho-Analysis 12:468-482.

Ferenczi, S. (1949[1933]) 'Confusion of the Tongues Between the Adults and the Child(The Language of Tenderness and of Passion). International Journal of Psycho-Analysis 30:225-230.

Forrester, J. (1980) Language and the Origins of Psychoanalysis. New York, Columbia University Press.

Freud, S. (1900) The Interpretation of Dreams. SE 5. London: Hogarth Press.

Freud, S. (1901)The Psychopathology of Everyday Life. SE 6. London: Hogarth Press. 
Freud, S. (1905) 'Fragment of an Analysis of a Case of Hysteria'. SE 7, pp. 1-122. London: Hogarth Press.

Freud, S. (1919) 'The 'Uncanny'. SE 17, pp. 217-256. London: Hogarth Press.

Freud, S. (1915) 'Overview of the Transference Neurosis'. In I. Grubrich-Simitis (ed.) A Phylogenetic Fantasy: Overview of the Transference Neuroses, Cambridge, Mass. and London: Belknap Press of Harvard University Press, 1987.

Freud, S. (1917) 'Introductory Lectures on Psycho-Analysis (Part III)'. SE 16, pp. 241-463. London: Hogarth Press.

Freud, (1933) 'Sandor Ferenczi'. SE 22, pp. 225-230. London: Hogarth Press.

Gerson, G. (2004) 'Object Relations Psychoanalysis as Political Theory'. Political Psychology 25 (5): 769-794;

Gerson, G. (2009a) 'Culture and Ideology in Ian Suttie's Theory of Mind'. History of Psychology 12(1): 19-40;

Gerson, G. (2009b) 'Ian Suttie's Matriarchy: A Feminist Utopia?'. Psychoanalysis, Culture \& Society 14: 375-392.

Glover, E. (1932) 'On the Aetiology of Drug-Addiction'. International Journal of PsychoAnalysis 13: 298-328.

Glover, J. (1927) 'Notes on an Unusual Form of Perversion'. International Journal of PsychoAnalysis 8:10-24.

Gould, S. J. (1977) Ontogeny and Phylogeny. Cambridge, Mass. and London: Belknap Press of Harvard University Press.

Gould, S. J. (2002) I Have Landed: the End of the Beginning in Natural History. London: Jonathan Cape. 
Greenberg, V.D. (1997) Freud and His Aphasia Book: Language and the Sources of Psychoanalysis. Ithaca: Cornell University Press.

Jones, E. (1931) 'The Problem of Paul Morphy—A Contribution to the Psycho-Analysis of Chess', International Journal of Psycho-Analysis 12:1-23.

Kitcher, P. (2007) Freud's Interdisciplinary Fiasco. In A. Brook (ed.) The Prehistory of Cognitive Science, Basingstoke: Macmillan, 2007.

Klein, M. (1927) 'Criminal Tendencies in Normal Children', British Journal of Medical Psychology 7(2): 177-192.

Laplanche, J. \& Pontalis, J.-B. (1973), The Language of Psycho-Analysis. London: Hogarth. Loughran T. (2007) 'Evolution, Regression, and Shell-Shock: Emotion and Instinct in Theories of the War neuroses, c.1914-1918'. Manchester Papers in Economic and Social History 58: 1-24.

McDougall, W. (1920) 'Four Cases of 'Regression' in Soldiers'. Journal of Abnormal Psychology 15 (2-3): 136-156.

Miller, G. (2007) 'A Wall of Ideas: The "Taboo on Tenderness" in Theory and Culture'. New Literary History 38 (4): 667-681.

Money-Kyrle, R. (1928) 'Morals and Super-Men'. British Journal of Medical Psychology 8(4):277-284.

Moreau-Ricaud, M. (1996) The Founding of the Budapest School. In P. L. Rudnytsky, A. Bokay, and P. Giampieri-Deutsch (Eds.) Ferenczi's Turn in Psychoanalysis. New York: New York University Press.

Moreau-Ricaud, M. (2002) 'Michael Balint: An Introduction'. American Journal of Psychoanalysis 62 (1): 17-24. 
Osborne, T. (1993) 'Mobilizing Psychoanalysis: Michael Balint and the General Practitioners'. Social Studies of Science 23(1): 175-200.

Otis, L. (1994) Organic Memory: History and the Body in the Late Nineteenth \& Early Twentieth Centuries. Lincoln and London: University of Nebraska Press.

Payne, S.M. (1939) 'Some Observations on the Ego Development of the Fetishist'. International Journal of Psycho-Analysis 20:161-170.

Richards, R. J. (2008) The Tragic Sense of Life: Ernst Haeckel and the Struggle Over Evolutionary Thought. Chicago and London: University of Chicago Press.

Rivers, W. H. R. (1922) Instinct and the unconscious: a contribution to a biological theory of the psycho-neuroses. Cambridge: Cambridge University Press.

Schmideberg, M. (1935) "Bad Habits' in Childhood; Their Importance in Development'. International Journal of Psycho-Analysis, 16:455-461

Sharpe, E. (1929) 'The Impatience of Hamlet'. International Journal of Psycho-Analysis 10: $270-279$.

Smith, C. U. M. (1982a) 'Evolution and the Problem of Mind: Part I. Herbert Spencer'. Journal of the History of Biology 15(1): 55-88.

Smith, C. U. M (1982b) 'Evolution and the Problem of Mind: Part II. John Hughlings Jackson'. Journal of the History of Biology 15(2):241-262.

Steiner, R. (2001) 'An Essay Marking Its Centenary: Some Observations on the Sources of Freud's The Psychopathology of Everyday Life'. Neuropsychoanalysis 3(2): 221-241.

Suttie, I. D. (1924) 'Metapsychology and Biology: Some criticisms of Freud's "Beyond the pleasure principle”'. The Journal of Neurology and Psychopathology 5(17): 61-70.

Suttie, I. D. (1932) 'Religion: Racial Character and Mental and Social Health'. British Journal of Medical Psychology 12(4): 289-314. 
Suttie, I. D. (1935a) The Origins of Love and Hate. London: K. Paul, Trench, Trubner.

Suttie, I. D. (1935b) 'A symposium on Property and Possessiveness'. British Journal of Medical Psychology 15(1): 51-83.

Suttie, I. D. \& Suttie, J. I. (1932) 'The Mother: Agent or Object? Part II'. British Journal of Medical Psychology 12(3):199-233.

Vikar, G. (1996) 'The Budapest School of Psychoanalysis'. In P. L. Rudnytsky, A. Bokay, and P. Giampieri-Deutsch (Eds.) Ferenczi's Turn in Psychoanalysis. New York: New York University Press.

Winnicott, D. W. (1957) The Child and the Outside World: Studies in Developing Relationships. London: Tavistock Publications.

Young-Bruehl, E. (2002), 'A Visit to the Budapest School'. Psychoanalytic Study of the Child $57: 411-432$.

\section{Electronic sources}

The Oxford English Dictionary Online, http://www.oed.com 